\title{
Nonsteroidal moulting hormone agonists: effects on protein synthesis and cuticle formation in Colorado potato beetle larvae
}

\author{
Guy Smagghe $^{1}$, Elisa Viñuela ${ }^{2}$, Heidi Van Limbergen ${ }^{1}$, Flor Budia ${ }^{2} \&$ Luc Tirry $^{1}$
}

\begin{abstract}
Larvae of the Colorado potato beetle, Leptinotarsa decemlineata (Say), that were orally treated with RH-0345 a $0.1 \mathrm{mg} \mathrm{l}^{-1}, \mathrm{RH}-5849$ at 10 and $50 \mathrm{mg} \mathrm{l}^{-1}$, tebufenozide at $2 \mathrm{~g} \mathrm{l}^{-1}$, and 20-hydroxyecdysone at $2 \mathrm{~g} \mathrm{l}^{-1}$, showec symptoms of premature moulting, followed by inhibition of ecdysis. In addition, fresh weight gain and total proteir content were blocked. The effects on haemolymphal and cuticular polypeptides after PAGE were linked with premature, new epicuticle deposition as was observed under the electron microscope. These observations suppor the concept that the ecdysteroid-mimicking action of the three nonsteroidal molecules is specific.
\end{abstract}

\section{Introduction}

In insects, moulting is cross-linked with protein synthesis and secretion of new exoskeleton, including a sequential deposition by the epidermal cells of cuticulin, epicuticle and a high number of procuticular lamellae. Hereto, ecdysteroids are released in the insect haemolymph and initiate apolysis at their peak level, thus affecting the proteosynthetic process and resulting in either a new, or an increased, or inhibited synthesis of some specific proteins. Further on, ecdysteroids have to be cleared from the body to guarantee successful post-apolysis processes such as deposition of the numerous procuticular lamellae, and ecdysis (Riddiford, 1985; Silvert, 1985; Apple \& Fristrom, 1991). In recent years, RH-5849 and tebufenozide (RH-5992) were introduced as the first synthetic agonists of ecdysteroids, a new group of insect growth regulators (IGRs) that can induce premature moulting, especially in larval Lepidoptera (Wing et al., 1988; Smagghe \& Degheele, 1992, 1994a; Dhadialla et al., 1998). More recently, a novel analogue of this family, RH-0345 (N-tert-butyl-N'-(4- chlorobenzoyl)benzohydrazide), has become available for investigational purposes and is expected to possess high toxicity against Coleoptera (RohMid, 1996).

The aim of this study is to provide further evidence for the ecdysteroid-like mode of action of this new group of IGRs in larvae of the Colorado potato beetle, Leptinotarsa decemlineata (Say). Herein, we elucidate the activity of the three nonsteroidal agonists towards last-instar larvae and their ability to affect pro tein synthesis in the cuticle and haemolymph, as does 20 -hydroxyecdysone $(20 \mathrm{E})$, in relation to premature induction of new cuticle synthesis and inhibition of procuticle formation. In addition, we evaluated the ultrastructure of this affected cuticle in comparison with a normal cuticle of untreated controls.

\section{Materials and methods}

Chemicals. Technical RH-0345 and RH-5849, and tebufenozide of technical and formulated $(240 \mathrm{~g}$ active ingredient/1) grade were supplied by Rohm and Haas 

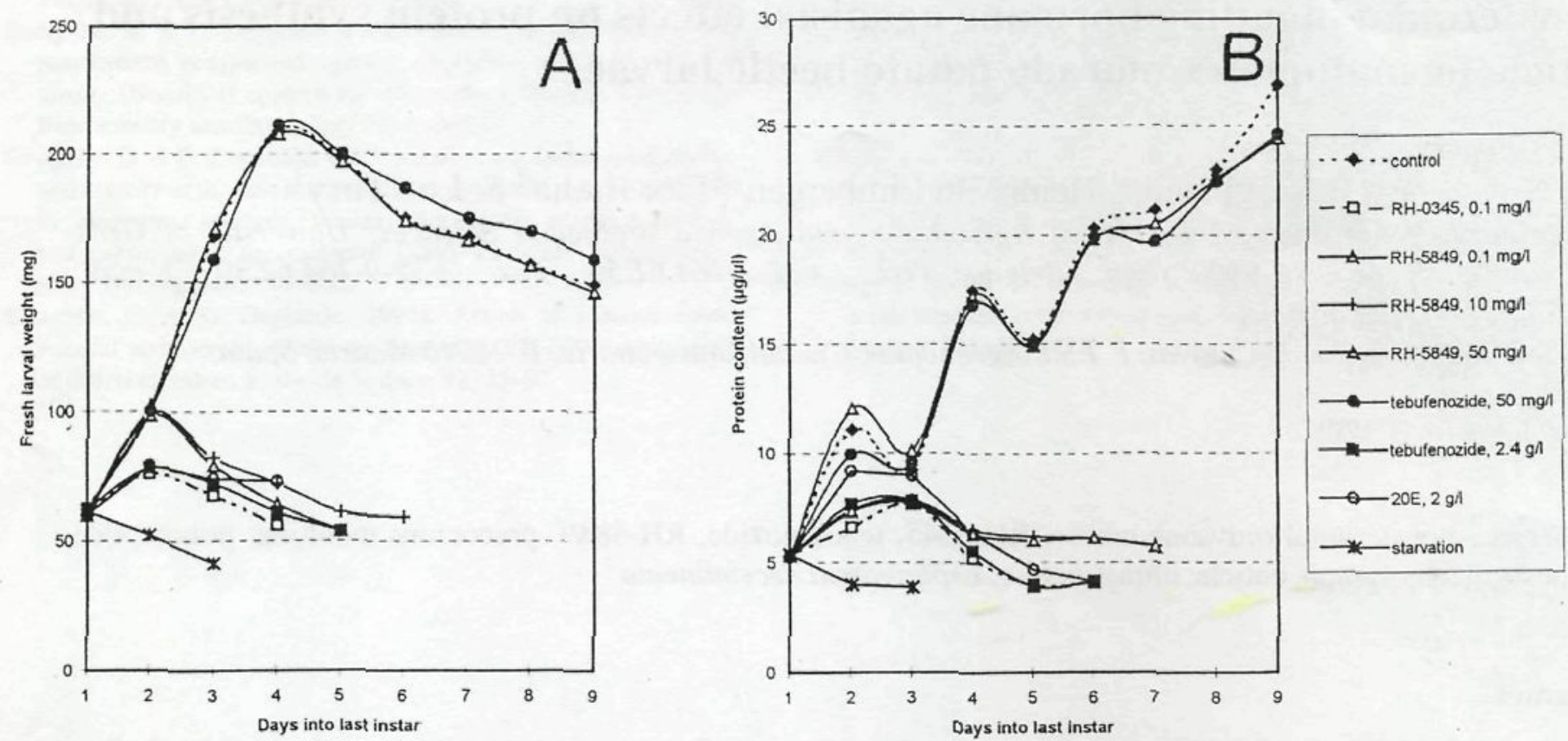

Figure 1. Fresh larval weight (1A) and haemolymphal protein content (1B) of control last-instar larvae of $L$. decemlineata, larvae after treatment with RH-0345 at $0.1 \mathrm{mg} \mathrm{l}^{-1}$, tebufenozide at $50 \mathrm{mg} \mathrm{l}^{-1}$ and $2.5 \mathrm{~g} \mathrm{l}^{-1}, \mathrm{RH}-5849$ at $0.1,10$ and $50 \mathrm{mg} \mathrm{l}^{-1}$, and 20-hydroxyecdysone (20E) at $2 \mathrm{~g} \mathrm{l}^{-1}$, and starved last-instar larvae. Mean weight and total protein values are based on five and three different measurcments, respectively; SEM values $<15 \%$ for weight and protein means.

$2 d$

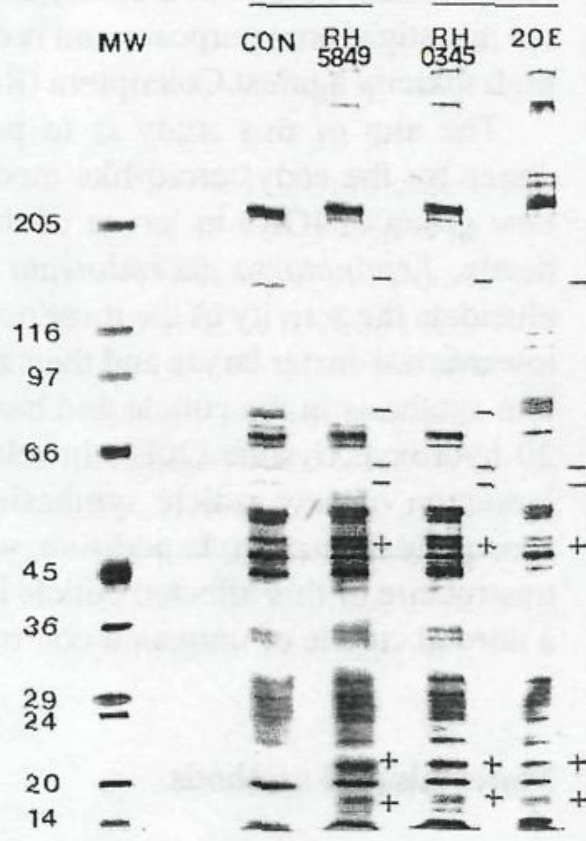

$6 \mathrm{~d}$

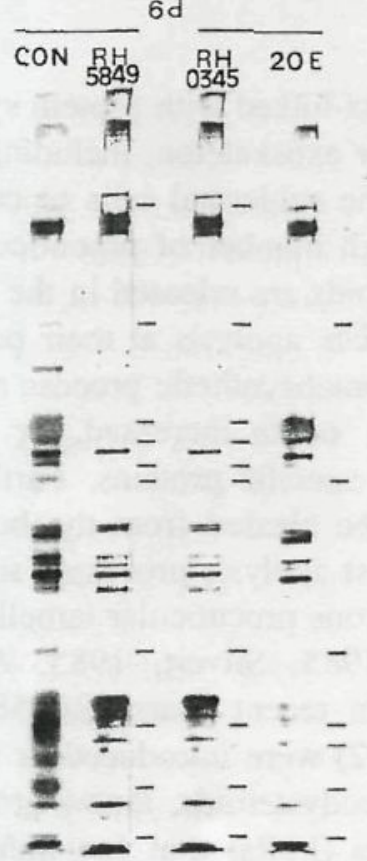

Figure 2. Haemolymphal polypeptide pattern of control (CON) last-instar larvae of $L$. decemlineata, and larvae after treatment with $\mathrm{RH}-0345$ at $0.1 \mathrm{mg} \mathrm{l}^{-1}, \mathrm{RH}-5849$ at $50 \mathrm{mg} \mathrm{l}^{-1}$, and 20-hydroxyecdysone at $2 \mathrm{~g}^{-1}(20 \mathrm{E})$ after $2(2 \mathrm{~d})$ and 6 days $(6 \mathrm{~d})$ of treatment into the last instar. + : induction, -: inhibition as compared with untreated control samples. 
(Spring House, PA, USA). 20E was purchased from Sigma (Bornem, Belgium).

Insects. All stages of $L$. decemlineata were fed on freshly cut potato leaves at standard conditions (Smagghe \& Degheele, 1993).

Oral treatment to assess moulting hormone effects. Freshly cut leaves were dipped for $10 \mathrm{~s}$ in an aqueous solution (containing $0.02 \%$ Triton X-100) of technical RH-0345, tebufenozide and RH-5849, dried in a fume-hood, and offered ad libitum to newly ecdysed ( $0-12$ h old) last-instar larvae. For RH-0345, we selected $0.1 \mathrm{mg} \mathrm{l}^{-1}$ based on a preliminary range test. For tebufenozide, we used $50 \mathrm{mg}^{-1}$ that was nontoxic, and $2.4 \mathrm{~g}^{-1}$ that induced precocious moulting; lower concentrations were not able to induce precocious moulting (Smagghe \& Degheele, 1994a). The $2.4 \mathrm{~g} \mathrm{l}^{-1}$ concentration of tebufenozide was prepared with the RH-5992-2F formulation without Triton X-100. For RH-5849, we selected 0.1, 10 and $50 \mathrm{mg} \mathrm{l}^{-1}$; the first concentration causing no abnormalities, whereas the latter two caused premature moulting (Smagghe \& Degheele, 1993). For 20E, a $2 \mathrm{~g} \mathrm{l}^{-1}$ concentration was prepared in methanol, and leaf discs of $1 \mathrm{~cm}$ diameter were treated uniformly, dried in a fume-hood and offered ad libitum. We also selected larvae that were starved from the start of the experiment onwards, in order to exclude indirect nonfeeding effects that could result from starvation due to double head capsule formation. Control larvae were provided with untreated potato leaves.

In all cases, mortality was scored after 11 days, and larvae were individually weighed daily from the start of the assay.

PAGE. Haemolymph samples were collected from a wound made by cutting off a mesothoracic leg, mixed with protein sample buffer $(0.1 \mathrm{M}$ Tris- $\mathrm{HCl}, \mathrm{pH} 8.8$, $1 \% \square$-mercaptoethanol, 3\% SDS, bromophenol blue and $10 \%$ glycerol; final concentrations), and then boiled for $5 \mathrm{~min}$. Polypeptides were separated on a $15 \times 15 \mathrm{~cm}$ polyacrylamide gradient gel $(7-15 \%)$, run at constant voltage of $200 \mathrm{~V}$. Gels were silver stained and air dried as described by Blum et al. (1987).

For cuticular protein analysis, two cuticles per sample were dissected in ice-cold Ringer, washed in ice-cold distilled water for $10 \mathrm{~min}$ and homogenized in a glass homogenizer with addition of distilled water (100 $\mu 1$ per $10 \mathrm{mg}$ wet fresh weight); the resulting suspension was centrifuged at $10000 \mathrm{~g}$ for $10 \mathrm{~min}$.

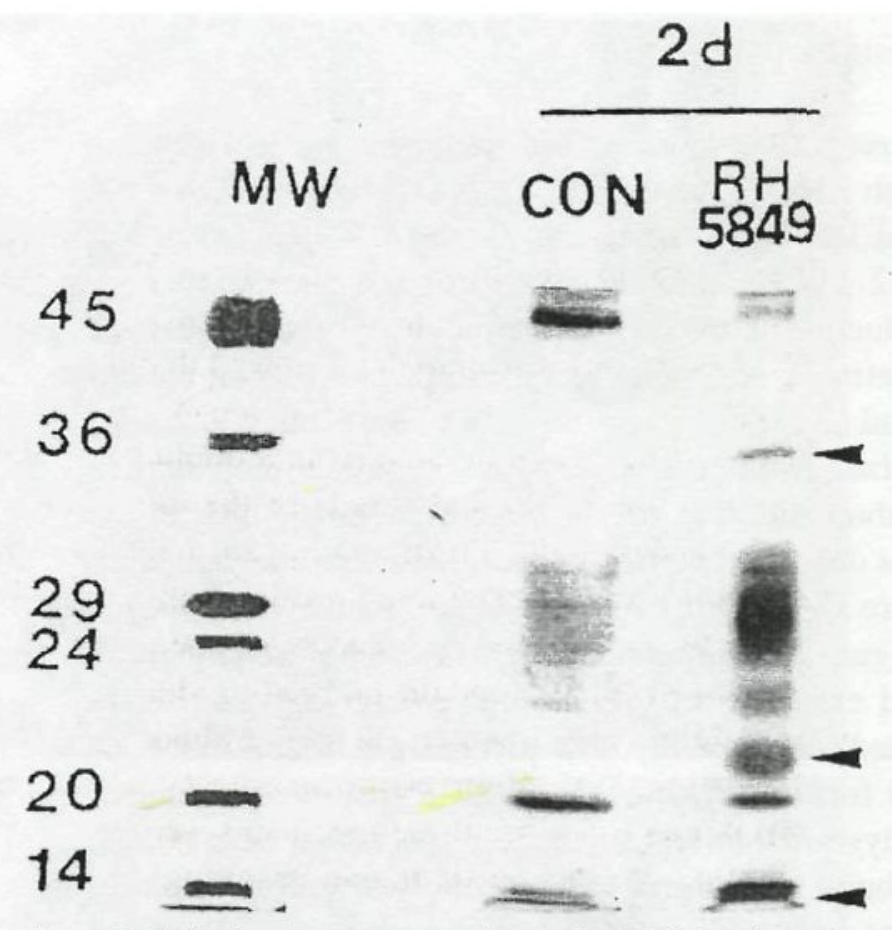

Figure 3. Cuticular protein pattern of control (CON) last-instar larvae of $L$. decemlineata, and larvae after treatment with RH-5849 at $50 \mathrm{mg} \mathrm{l}^{-1}$ after 2 days of treatment into the last instar. $\leftarrow$ : induction as compared with untreated control samples.

Electrophoretic separation of $10 \mu 1$ supernatant was performed on a $25 \times 12 \mathrm{~cm}$ native polyacrylamide gradient gel $(5.5-11.1 \%)$ at $20 \mathrm{~mA}$ for $2.5 \mathrm{~h}$, and gels were stained with Coomassie blue R-250 (Smagghe \& Degheele, 1992).

Protein measurements were done using Bradford's method (1976) with BSA as standard. A low and high molecular weight protein standard series of Sigma (Bornem, Belgium) were run on each gel.

Electron microscopy. Newly ecdysed ( $0-30$ min old) last-instar larvae were collected and treated with RH5849 at $50 \mathrm{mg} \mathrm{l}^{-1}$ as described above. At different intervals, dorsal mesothoracic integument tissues were dissected in ice-cold Ringer, and double fixed in $2.5 \%$ glutaraldehyde and $1 \% \mathrm{OsO}_{4}$. Tissues were dehydrated with ethanol and propylene oxide and embedded in ERL, and thin sections were made with an Ultracut E microtome (Reichert/JWG) and stained with uranyl acetate and lead citrate prior to observation in a Zeiss-902 electron microscope (Smagghe et al., 1996). 


\section{Results}

Larvicidal toxicity. Oral treatment via leaf dipping with RH-0345 at $0.1 \mathrm{mg} \mathrm{l}^{-1}$, tebufenozide at $2.4 \mathrm{~g} \mathrm{l}^{-1}$ and RH-5849 at 10 and $50 \mathrm{mg} \mathrm{l}^{-1}$, and with $20 \mathrm{E}$ at $2 \mathrm{~g} \mathrm{l}^{-1}$, inhibited growth of last-instar larvae by inducing premature larval moulting within $48 \mathrm{~h}$ of treatment. Binocular examination showed that the old head capsule slipped down, revealing a new nonsclerotized head capsule. Larvae died in a double cuticle without splitting of the old cuticle or the old cuticle was only shed partially. Fresh weight gain and feeding were significantly blocked as compared with controls (Figure 1A). In some cases, bleeding of haemolymph and extrusion of the hindgut preceeding death were noted. Additionally, low percentages of abnormal pupal formation were observed in treatments at pupal ecdysis in controls since these specimens were unable to build up a normal pupal cuticle, resulting in larvapupa intermediate mosaics. In contrast, tebufenozide and $\mathrm{RH}-5849$, at 50 and $0.1 \mathrm{mg}^{-1}$, respectively, had no effect on the development since these larvae increased in weight (Figure 1A) and underwent successful pupation similar to controls.

Newly moulted last-instar larvae of $L$. decemlineata that were starved died after 2 days without any increase in fresh weight (Figure 1A).

Electrophoresis. The total protein content in haemolymph of last-instar larvae, treated with $0.1 \mathrm{mg} \mathrm{l}^{-1}$ $\mathrm{RH}-0345,2.5 \mathrm{~g} \mathrm{l}^{-1}$ tebufenozide, 10 and $50 \mathrm{mg} \mathrm{l}^{-1}$ RH-5849, and $2 \mathrm{~g}^{-1} 20 \mathrm{E}$ showed a small increase on the first day after treatment and then dropped down until about 4-7 $\mu \mathrm{g} \mu \mathrm{l}^{-1}$ (Figure 1B). In case of the starved larvae, the total protein level remained low (4 $5 \mu \mathrm{g} \mu \mathrm{l}^{-1}$ ) until death at day 2 . In the controls, the protein content curve increased from 5 to $27 \mu \mathrm{g} \mu \mathrm{l}^{-1}$ (Figure 1B).

The synthesis of at least three haemolymphal polypeptides with a weight of about 19,22 and $48 \mathrm{kDa}$ was induced at day 2 after treatment with $0.1 \mathrm{mg} \mathrm{l}^{-1}$ RH-0345, $2 \mathrm{~g} \mathrm{l}^{-1}$ tebufenozide and $50 \mathrm{mg} \mathrm{l}^{-1} \mathrm{RH}-$ 5849 , and $2 \mathrm{~g}^{-1} 20 \mathrm{E}$ (Figure 2). It should be remarked that the polypeptide band of $48 \mathrm{kDa}$ was a minor component of the 20E-pattern. Treatment with $50 \mathrm{mg}^{-1}$ tebufenozide and $0.1 \mathrm{mg} \mathrm{^{-1 }}$ RH-5849 showed no effects as compared with controls. In larvae starved for $2 \mathrm{~d}$, the 19 and $48 \mathrm{kDa}$ polypeptides were not recorded, while the synthesis in the haemolymph of two polypeptides of about 22 and $32 \mathrm{kDa}$ was stimulated as compared with controls. In addition, the production of a 12,22 and $35 \mathrm{kDa}$ cuticular protein (Figure 3) was stimulated after $2 \mathrm{~d}$ of treatment with $\mathrm{RH}-5849$ at $50 \mathrm{mg}^{-1}$ and tebufenozide at $2.4 \mathrm{~g} \mathrm{l}^{-1}$. No effects were seen with tebufenozide at $50 \mathrm{mg} \mathrm{l}^{-1}$ as compared with untreated larvae (not shown).

Treatment with $0.1 \mathrm{mg} \mathrm{l}^{-1} \mathrm{RH}-0345,2.5 \mathrm{~g} \mathrm{l}^{-1}$ tebufenozide and $50 \mathrm{mg} \mathrm{l}^{-1} \mathrm{RH}-5849$ also arrested the production of four haemolymph polypeptides (about $59,62,75$ and $150 \mathrm{kDa}$ ) during the first $2 \mathrm{~d}$ of treatment as compared with controls. $20 \mathrm{E}$ at $2 \mathrm{~g} \mathrm{l}^{-1}$ also inhibited synthesis of 59,62 and $150 \mathrm{kDa}$ polypeptides. So, the polypeptide band of $75 \mathrm{kDa}$ was present after treatment with $20 \mathrm{E}$, whereas this was missing with either RH-compound. Then, at day 6 after treatment, few haemolymph polypeptides of about $16,21,24,34$, $64,66,69,82,125$ and $250 \mathrm{kDa}$, were no longer synthesized due to treatment with $0.1 \mathrm{mg} \mathrm{l}^{-1} \mathrm{RH}-0345$, $2.5 \mathrm{~g} \mathrm{l}^{-1}$ tebufenozide and $50 \mathrm{mg} \mathrm{l^{-1 }} \mathrm{RH}-5849$. This agrees with the observation in larvae treated with $20 \mathrm{E}$ at $2 \mathrm{~g} \mathrm{l}^{-1}$ where we saw inhibition of polypeptides of about 16, 21, 24, 34, 64 and $125 \mathrm{kDa}$ (Figure 2). Interestingly, the latter bands were clearly observed in untreated controls from $6 \mathrm{~d}$ after ecdysis into the last instar onwards, representing the time of endocuticular deposition. Cuticular protein gels revealed analogous results as those for haemolymph polypeptides. In larvae treated with $2.5 \mathrm{~g} \mathrm{l}^{-1}$ tebufenozide and $50 \mathrm{mg} \mathrm{l}^{-1}$ RH-5849, the synthesis of five proteins of about 24 , $36,45,96$ and $150 \mathrm{kDa}$ was arrested, while in untreated controls (protein extract samples prepared at day $2,4,6,8$ and 11) these bands were highly expressed from day 6 after ecdysis into the last instar until pupal ecdysis at day 11. Protein samples of larvae treated with tebufenozide at $50 \mathrm{mg} \mathrm{l}^{-1}$ revealed a similar pattern as in controls (not shown).

Electron microscopy. Twelve hours after treatment with RH-5849 at $50 \mathrm{mg} \mathrm{l}^{-1}$, symptoms of precocious apolysis were noted, as was also the case with $20 \mathrm{E}$ at $2 \mathrm{~g} \mathrm{l}^{-1}$. We noted in the epidermal cytoplasm an increased amount of vacuoles, endoplasmatic reticulum, Golgi complexes, and numerous mitochondria, coated vesicles, myelin figures and glycogen (Figure 4AC). Initial ecdysial space formation and weak signs of ecdysial membrane secretion were seen as some of the epidermal microvilli had detached from the old cuticle. Figure 4D exemplifies deposition of new cuticulin patches at the microvilli tips. Later, at $48 \mathrm{~h}$ after treatment (Figure 5A), the ecdysial space between the old cuticle and epidermis was predominant, and new pharate cuticle secretion was noted as the formation 

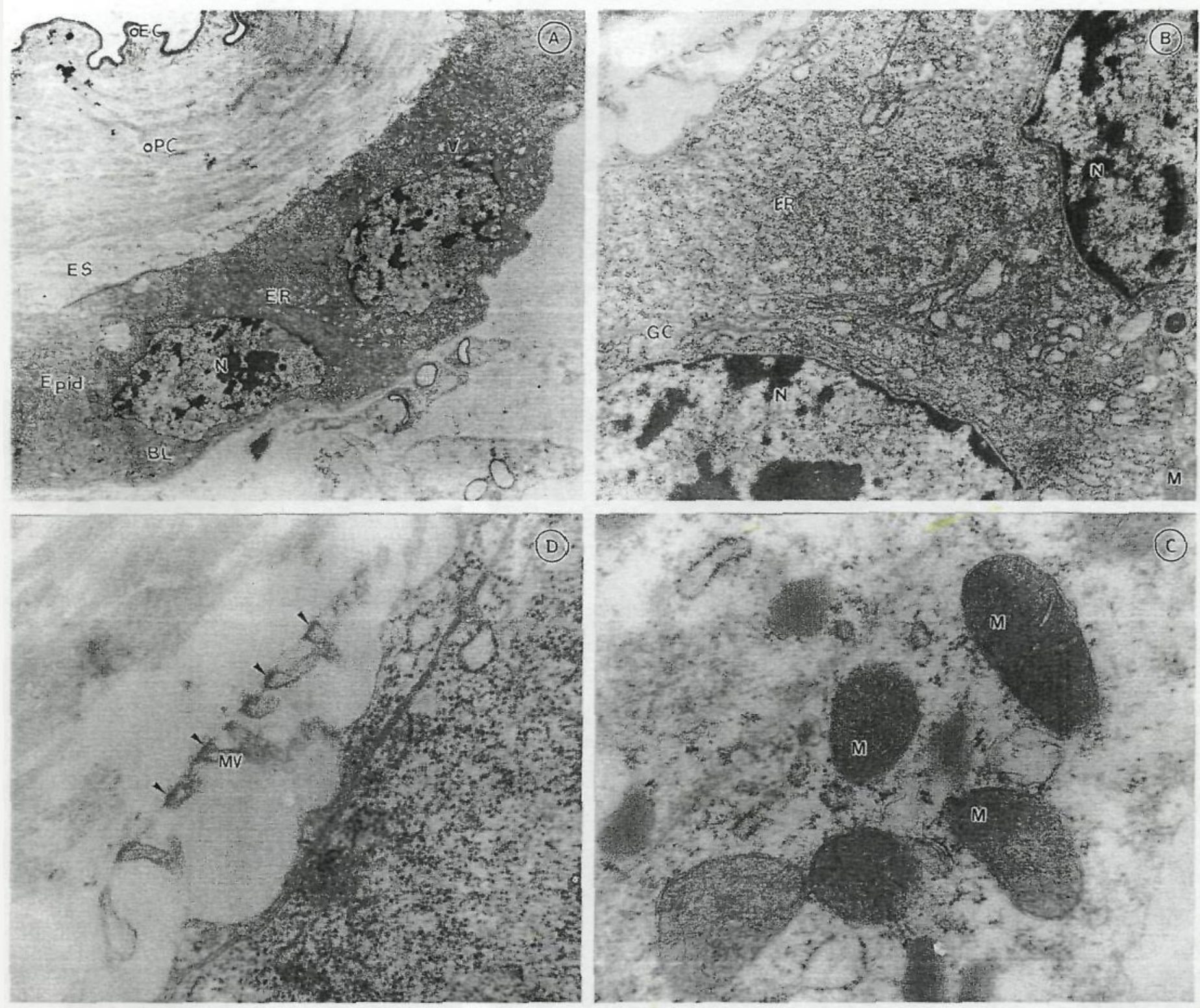

Figure 4. Electron microscopic dorsal integument section of a $L$. decemlineata last-instar larva treated for $12 \mathrm{~h}(\mathrm{~A}-\mathrm{D})$ with $50 \mathrm{mg} \mathrm{l^{-1 }}$ RH-5849. Induction of premature apolysis leading to new cuticle formation. After $12 \mathrm{~h}$ of treatment, epidermal cells contained numerous vacuoles and vesicles (V), endoplasmatic reticulum (ER), Golgi complexes (GC) and mitochondria (M) (4A-C). Plate 4D shows in detail clear signs of new cuticulin patches (small arrows) secretion at the tips of the epidermal microvilli (MV). BL: basal lamina, ES: ecdysial space, N: epidermal nucleus, oEC: old epicuticle, oPC: old procuticle. 4A: ×4400; 4B: $\times 12000 ; 4 \mathrm{C}: \times 30000 ; 4 \mathrm{D}: \times 30000$.

of a new cuticulin layer was followed by a dense new epicuticle and some fibrous cuticular material, leading to the presence of a double cuticle. After $6 \mathrm{~d}$, the new epicuticle coated an incomplete new procuticle containing only a low number of lamellae, ranging from 3 to 12 (Figure 5B). This was in great contrast to normal procuticle formation in controls since the latter contained around 100 lamellae (Figure 5C). In addition, the epidermal cells of intoxicated larvae degenerated, (Figure 5D), the old procuticle was partially digested probably by the moulting fluid, and normal shedding of the old epicuticle was obviously inhibited.

\section{Discussion}

For $L$. decemlineata larvae, we demonstrated that RH0345 at $0.1 \mathrm{mg} \mathrm{l}^{-1}$, tebufenozide at $2.5 \mathrm{~g} \mathrm{l}^{-1^{*}}$ and RH5849 at 10 and $50 \mathrm{mg}^{-1}$, led to an untimely induced and lethal larval moulting as was also the case with the natural insect moulting hormone $20 \mathrm{E}$ at $2 \mathrm{~g} \mathrm{l}^{-1}$.

$\mathrm{RH}$-compounds induced the formation of a new pharate epicuticle within $24 \mathrm{~h}$ after treatment. From SDS-PAGE, this effect was related with induction of polypeptides of about 19 and $48 \mathrm{kDa}$ in the haemolymph and of proteins of about 12, 22 and $35 \mathrm{kDa}$ in the cuticle. Induced synthesis of these 

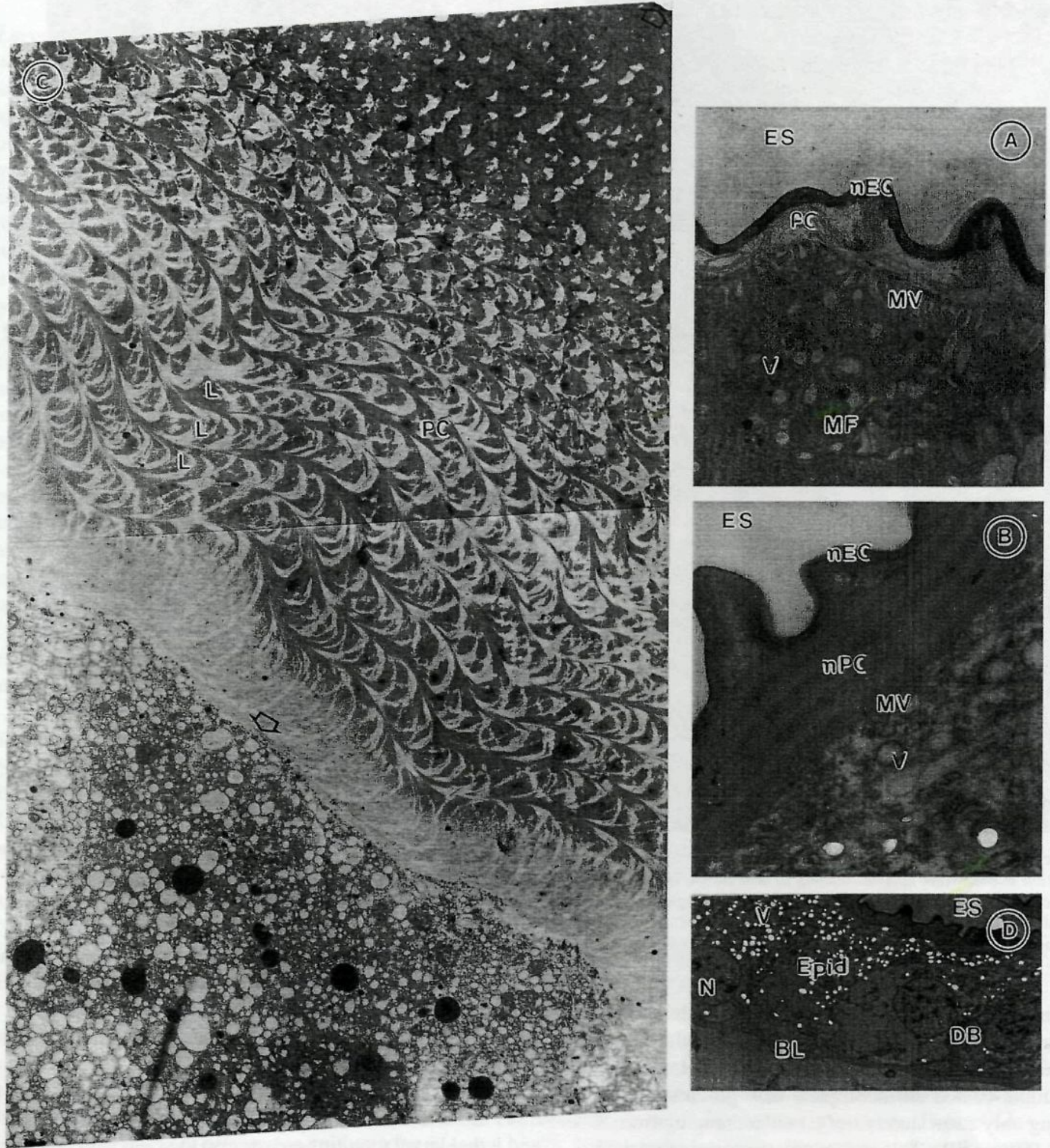

Figure 5. Electron microscopic dorsal integument section of a $L$. decemlineata last-instar larva treated for $48 \mathrm{~h}(5 \mathrm{~A})$, and $6 \mathrm{~d}(5 \mathrm{~B}-\mathrm{D})$ with $50 \mathrm{mg}^{-1} \mathrm{RH}-5849$. Presence of a double cuticle. Clear signs of new epicuticle (nEC) secretion were visible at the tips of the epidermal microvilli (MV), followed by fibrous cuticle (fC) production (6A). However, the high number of procuticular lamellae (nPC; L) was conspiciously absent (5B). This was in clear contrast to the thickness of a normal integument of control larvae that showed 100 lamellae (5C). Plate 6D shows that the epidermal cells (Epid) in treated larvae contained numerous vacuoles and vesicles (V), dense bodies (DB) and revealed drastic signs of degeneration. BL: basal lamina, ES: ecdysial space, MF: myelin figure, N: epidermal nucleus, oEC: old epicuticle, oPC: old procuticle. 5A: $\times 12000$; 5B: $\times 20000$; 5 : $\times 3000$; 5D: 2500 . 
transcripts was also observed in larvae treated with $20 \mathrm{E}$, resulting in precocious moulting. So, we suggest these polypeptides to be ecdysteroid-specific. Overall, we found similarity in the manner of polypeptide expression by $20 \mathrm{E}$ and the RH-compounds, suggesting that the primary mode of action of these nonsteroids in larvae of $L$. decemlineata is ecdysteroid-like and induces initial formation of new cuticle. The small differences in 20E-polypeptide pattern and that of the $\mathrm{RH}$-compounds might indicate that these nonsteroids might not be fully capable to mimic all the aspects of the ecdysteroid hormone action in the insect.

A second approach taken in this research was to evaluate whether the newly induced cuticle by the RHcompounds was normal and complete. It is known that many cellular events which occur between apolysis and ecdysis, depend on the fall of the ecdysteroid titre. For instance, dopamine is required for precursor production needed for sclerotization of the newly deposited cuticle (Riddiford, 1985; Hopkins \& Kramer, 1992). Lack of the latter could have resulted in the new head capsule that is non-sclerotized which was seen after treatment with RH-compounds. Similarly, $\mathrm{LCP}_{14}$ production normally appears just before ecdysis as the lamellated endocuticle is deposited (Hiruma et al., 1991). As such RH-compounds are metabolically stable and show a significant persistence in the insect body (Smagghe \& Degheele, 1993, 1994b; Dhadialla et al., 1998) in contrast to ecdysteroids as 20E (Koolman \& Karlson, 1985), it is reasonable to expect that these nonsteroidal agonists stimulate the early processes of moulting and at a later stage inhibit the developmental processes. Lack of lamellated procuticle in treated larvae agrees with the current electromicroscopic observations in $L$. decemlineata integument and those of Binnington \& Retnakaran (1991) in caterpillars of the spruce budworm, Choristoneura fumiferana Clemens. Retnakaran et al. (1995) also demonstrated that RH-5849 and tebufenozide suppressed the expression of genes for endocuticular proteins and for DOPA-decarboxylase, which is required for sclerotization. It is striking that they observed a similar inhibition in the presence of high doses of 20E. In a similar manner, application of $\mathrm{RH}$-compounds may have inhibited the production of several high molecular-weight haemolymph and cuticular polypeptides which may be pupa-specific, since they appeared after pupal apolysis in the control. Lack of such polypeptides may have helped in causing larva-pupa intermediates in treatments.

\section{Acknowledgements}

The authors are grateful to Dr G. R. Carlson (Rohm and Haas Research Laboratories, Spring House, PA, USA) for providing $\mathrm{RH}-0345$, tebufenozide and $\mathrm{RH}-$ 5849. Dr G. Smagghe is a post-doctoral fellow from the National Fund for Scientific Research, Brussels. This research was supported by projects AGF93-1174 and UR93-0597 to Dr E. Viñuela from the Spanish Ministry of Education (DGICYT), and projects 950162 and 970288 to Dr G. Smagghe from the IWT (Flemish Institute for Encouragement of ScientificTechnological Research in Industry). The authors are also indebted to Mrs B. Roos (Laboratory of Agrozoology) for good technical assistance on protein measurements.

\section{References}

Apple, R. T. \& J. W. Fristrom, 1991. 20-Hydroxyecdysone is required for, and negatively regulates, transcripts of Drosophila pupal cuticle proteins. Developmental Biology 146: 569-582.

Binnington, K. \& A. Retnakaran, 1991. Epidermis - a biological active target for metabolic inhibitors. In: K. Binnington \& A. Retnakaran (eds), Physiology of the Insect Epidermis, CSIRO, Australia, pp. 307-334.

Blum, H., H. Beier \& H. J. Gross, 1987. Improved silver staining of plant proteins, RNA and DNA in polyacrylamide gels. Electrophoresis 8: 93-99.

Bradford, M. M., 1976. A rapid and sensitive method for the quantification of microgram quantities of protein utilizing the principle of protein-dye binding. Analytical Biochemistry 72 : 248-254.

Dhadialla, T. S., G. R. Carlson \& D. P. Le, 1998. New insecticides with ecdysteroid and juvenile hormone activiity. Annual Review of Entomology 43: 545-569.

Hiruma, K., J. Hardie \& L. M. Riddiford, 1991. Hormonal regulation of epidermal metamorphosis in vitro: control of expression of a larval-specific cuticle gene. Developmental Biology 144: 369-378.

Hopkins, T. L. \& K. J. Kramer, 1992. Insect cuticle sclerotization. Annual Review of Entomology 37: 273-302.

Koolman, J. \& P. Karlson, 1985. Regulation of ecdysteroid titer: Degradation. In: G. A. Kerkut \& L. I. Gilbert (eds), Comprehensive Insect Physiology, Biochemistry and Pharmacology, Vol. 7. Pergamon Press, Oxford, pp. 343-361.

Retnakaran, A., K. Hiruma, S. R. Palli \& L. M. Riddiford, 1995. Molecular analysis of the mode of action of RH-5992, a lepidopteran-specific, non-steroidal ecdysteroid agonist. Insect Biochemistry and Molecular Biology 25: 109-117.

Riddiford, L.M., 1985. Hormonal action at cellular level. In: G. A. Kerkut \& L. I. Gilbert (eds.), Comprehensive Insect Physiology, Biochemistry and Pharmacology, Vol. 8. Pergamon Press, Oxford, pp. 37-84.

RohMid, 1996. Technical information bulletin. RH-0345, turf and ornamental insecticide. RohMid L.L.C., Philadelphia, PA, USA, $12 \mathrm{p}$.

Silvert, D. J., 1985. Cuticular proteins during postembryonic development. In: G. A. Kerkut \& L. I. Gilbert (eds.), Comprehensive 
Insect Physiology. Biochernistry and Pharmacology, Vol. 2. Pergamon Press, Oxford, pp. 239-254.

magghc. G. \& D. Degheele, 1992. Effects of RH-5849, the first nonsteroidal ecdysteroid agonist, on larvae of Spodoptera littoralis (Boisd.) (Lepidoptera: Noctuidae). Archives of insect Biochemistry and Physiology 21: 119-128.

magghe, G. \& D. Degheele. 1993. Metabolism. pharmacokinetics, and toxicity of the first nonsteroidat ecdysteroid agonist RH 5849 to Spodoptera exempta (Walker), Spodoptera exigua (Hübner), and Leptinotarsa decemlineata (Say). Pesticide Biochemistry and Physiology 46: 149-160.

nagghe. G. \& D. Degheele. 1994a. Action of a novel nonsteroidal ecdysteroid mimic tebufenozide (RH-5992) on insects of different orders. Pesticide Science 42: 85-92.
Smagghe. G. \& D. Degheele. 1994b. Significance of pharmacokinetics and metabolism to the biological activity of RH-5992 (tebufenozide) in Spodopterci exempta, Spodoptera exigua, and Leptinotarsa decemlineata. Pesticide Biochemistry and Physio!ogy 49: 224-234.

Smagghe, G. E. Viñuela, F. Budia \& D. Degheele. 1996. In wo and in witro effects of the nonsteroidal ecdysteroid agonist tebufenozide on cuticle fonnation in Spodoptera exiguta: an ultrastructural approach. Archives of Insect Biochemistry and Physiology 32: 121-134.

Wing, K. D. R. A. Slawecki \& G. R. Carison, 1988. RH-5849, a nonsteroidal ecdysone agonist: effects on farval Lepidoptera. Science 241: 470-472. 